\title{
COMPARISON OF NON-RADIOGRAPHIC SPONDYLOARTHRITIS VERSUS ANKYLOSING SPONDYLITIS PATIENTS UNDERGOING BIOLOGICAL THERAPY - DATA FROM A ROMANIAN COHORT
}

\author{
Claudia Deaconu ${ }^{1}$, Daniela Opris ${ }^{1,2}$, Ruxandra Ionescu ${ }^{1,2}$ \\ ${ }^{\prime}$ Department of Rheumatology and Internal Medicine, \\ Sfanta Maria Clinical Hospital, Bucharest, Romania \\ ${ }^{2}$ Carol Davila University of Medicine and Pharmacy, Bucharest, Romania
}

Abstract
Both non-radiographic spondyloarthritis (nr-SpA) and ankylosing spondylitis (AS) are medical conditions that be-
long to the axial spondyloarthritis spectrum; these two terms reveal the extent of sacroilitis assessed by conven-
tional x-ray or MRI. According to the latest classification criteria (ASAS, 2009), clinicians are able to differentiate
patients with nr-SpA from AS and to follow their disease progression.
The present study aims to compare the two patient categories undergoing biological therapy with an anti-TNF
agent and indicate distinct disease features. We included 94 patients in treatment with IFX, ADL, ETA or GOL and
monitored clinical, biological and disease activity parameters.
The nr-SpA subgroup included a higher percentage of female patients; AS patients presented higher values of
the CRP at follow-up visits; there were no significant differences between the two groups regarding the HLA-B27
presence, uveitis history or smoking status.
Patients with an inactive disease status had a lower BMI, shorter disease duration and an early initiation of biologi-
cal therapy, so that we suggest a close and regular monitoring of these two entities.
Keywords: non-radiographic spondyloarthritis, ankylosing spondylitis, anti-TNF therapy, radiographic progression, window of opportunity

\section{INTRODUCTION}

The spondyloarthritidis ( $\mathrm{SpA}$ ) group share similar axial manifestations and radiographic changes, with ankylosing spondylitis (AS) being the main representative. The typical radiographic finding is sacroiliitis which belongs to the modified New York classification criteria (1984) (1). The latter require the presence of stage 2 to 4 bilateral sacroiliitis or grade 3 to 4 unilateral sacroiliitis for the diagnosis of AS (2). However, these lesions can develop after a period that can last up to several years after the first symptoms occur or they can remain absent during the evolution of the disease. These findings led to the hypothesis that there could be an initial pre-radiographic phase that precedes the radiographic stage (3).

The need to establish an early diagnosis advanced the elaboration of a new set of classification criteria
(ASAS, 2009) that targeted the identification of nonradiographic forms of the disease (4). These include as imaging criteria the presence of lesions indicating active, acute inflammation on MRI which are highly indicative of SpA associated sacroiliitis (2).

The concept of pre-radiographic SpA suggests a later patient progression to a radiographic stage of the disease, but evidence regarding this evolution is rather scarce. Therefore, the term of non-radiographic $\mathrm{SpA}(\mathrm{nr}-\mathrm{SpA})$ is preffered (6). This term should be addressed to patients exhibiting AS clinical symptoms but showing no radiographic changes of the sacroiliac joints (7).

A study run by Bennett in 2008 observed the imaging progression of patients with sacroiliitis detected on MRI at eight years. Out of the total of $50 \mathrm{pa-}$ tients included in the study cohort that fulfilled the ESSG criteria (European Spondylarthropathy Study

Correspondence address:

Claudia Deaconu, Sfanta Maria Clinical Hospital, Bucharest, 37-39 Ion Mihalache Bd, District 1, Bucharest, Romania

E-mail: claudiadeaconu1@yahoo.com 


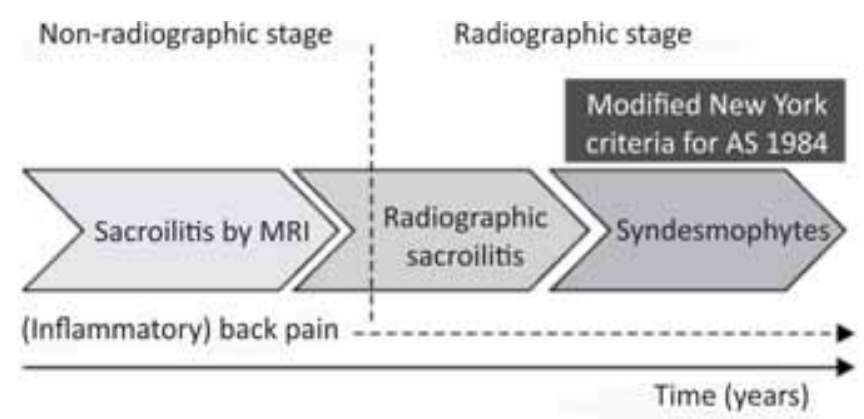

FIGURE 1. The concept of axial spondyloarthritis Source: Adapted from Rudwaleit M., 2005 (5)

Group), only 30\% presented X-ray changes of sacroiliitis at the eight year follow-up (8).

Similarly, out of the German GESPIC cohort, only $11.6 \%$ patients with nr-SpA developed radiographic sacroiliitis detected at the two-year followup, having as progression predictors a high level of C-reactive protein (CRP) at baseline (9).

The existence of nr-SpA as a distinct entity is also suggested by a French study on genetic studies for SpA (Groupe Français d'Etude Génétique des Spondylarthropathies) that proved a higher incidence of radiographic sacroiliitis in patients with longer disease duration and that approximately $60 \%$ of patients require a minimum of ten years of active disease to develop radiographic transformation (7).

The prevalence of AS is relatively well known worldwide, varying from $0.01 \%$ in Japan to 0.3 $0.9 \%$ in Europe and America, depending on the HLA B27 gene distribution in the population (10). However, epidemiological data on nr-SpA are still to be observed. A retrospective cohort study in America estimated a prevalence of $0.3 \%$ for $\mathrm{nr}-\mathrm{SpA}$ (11).

The natural history of $\mathrm{nr}-\mathrm{SpA}$ follows various evolution patterns; a percentage of patients further develop AS; smoking, male gender, high levels of inflammatory markers or initial radiographic lesions are among predictor factors of progression (12). However, a number of patients can be affected by nr-SpA, with no obvious x-ray lesions. Thus, identifying individual characteristics of patients with nr$\mathrm{SpA}$ in order to monitor and accurately predict the evolution of this patient category would be of real use in daily practice.

\section{OBJECTIVES}

The objective of the present study was to compare features of nr-SpA patients versus AS patients undergoing biological therapy with an anti-TNF agent, based on data from real life in a Romanian cohort.

\section{MATERIALS AND METHODS}

\section{Recruiting patients}

This was an observational, cross-sectional study. Between February to August 2016, we collected a number of 94 patients with nr-SpA and AS that were under medical supervision in the Department of Rheumatology of the "Sfanta Maria" Clinical Hospital staff.

Patients were under continuous biological therapy with an anti-TNF agent, namely adalimumab (ADL), infliximab (IFX), etanercept (ETA) or golimumab (GOL) for at least six months and following the inclusion criteria imposed by local guidelines.

\section{Ethical aspects}

Patients or legal representatives (if necessary) were informed on personal data usage during the study and they signed an informed consent sheet; the study was approved by the Ethics Committee in the "Sfanta Maria" Hospital.

\section{Statistical analysis}

Version 20.0 of the SPSS program was used to analyze data in the study, setting a significant $P$ value of 0.05 . Results are expressed as mean values \pm standard deviation (SD) where stated. Differences between independent group variables were tested using the t-student test.

\section{RESULTS}

Out of the selected study group, 69 patients were diagnosed with AS having a mean age of $44.8 \pm 10.8$, while 25 patients had nr-SpA. Patients with nr-SpA were aged $32.1 \pm 6.6$ years old and $40 \%$ of them were women. The age difference between the two subgroups is significant $(p<0.01)$, in that patients with AS had a higher age compared to the nr-SpA. 
$27.5 \%$ of patients with AS were women. This subgroup had a higher age at the beginning of their symptoms. Mean age at disease onset was 30.7 years for this subgroup versus only 23.8 years for patients with nr-SpA $(\mathrm{p}<0.01)$.

In the study cohort, $69 \%$ of patients were males, and the predominant group age was situated between 30 to 40 years old, with a percentage of $29.8 \%$. The entire patient distribution based on age groups can be observed in the following figure.

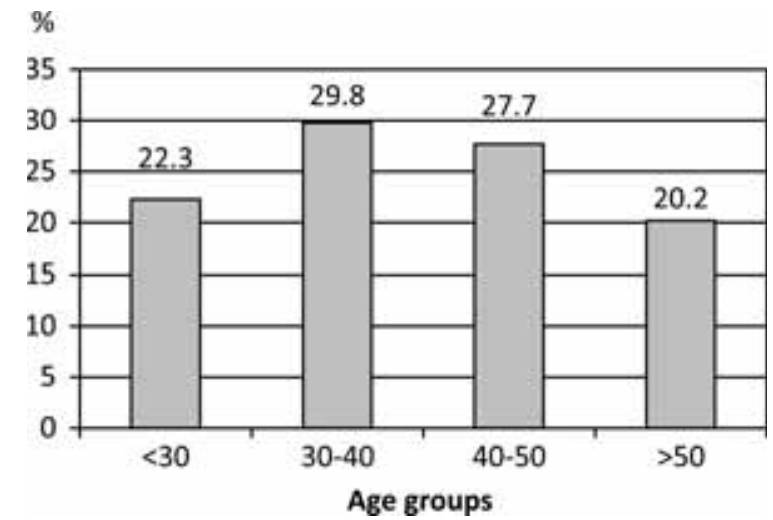

FIGURE 2. Patient distribution based on age groups

AS patients presented a significantly higher value of the BMI (body mass index) compared to patients with $\mathrm{nr}-\mathrm{SpA}\left(27\right.$ versus $\left.24.7 \mathrm{~kg} / \mathrm{m}^{2}\right)$.

91\% of patients had a positive HLA B27 detection and $7.4 \%$ had a positive family history of SpA.

Data comparison between the two subgroups is included in Table 1.

There were significant differences regarding female rates in the nr-SpA subgroup compared to AS $(\mathrm{P}=0.05)$. A higher level of CRP was noticed in AS patients $(\mathrm{P}=0.038)$.

TABLE 1. Similarities and differences between AS and nr-SpA patients

\begin{tabular}{|l|c|c|}
\cline { 2 - 3 } \multicolumn{1}{c|}{} & AS & nr-SpA \\
\cline { 2 - 3 } \multicolumn{1}{c|}{} & $\mathrm{N}=69$ & $\mathrm{~N}=25$ \\
\hline Age, years & 44.87 & 32.12 \\
\hline HLA-B27 (+) \% & 91.3 & 92 \\
\hline Females, \% & 27.5 & 40 \\
\hline BASDAI (0-10) & 1.74 & 1.16 \\
\hline PtGA (0-10) & 2.26 & 1.44 \\
\hline Abnormal CRP, \% & 37.6 & 20 \\
\hline Uveitis, \% & 20 & 8 \\
\hline Smokers, \% & 21.7 & 28 \\
\hline
\end{tabular}

Abbreviations: BASDAI (Bath Ankylosing Spondylitis Disease Activity Index), PtGA (Patient Global Assessment), CRP (C-reactive protein)

Out of the total 94 patients, $48 . \%$ had ADL treatment, $8.5 \%$ with IFX while $40.4 \%$ were under ETA therapy. The rest of $2.1 \%$ ( 2 patients) had GOL as treatment.

In the nr-SpA subgroup, most patients, $56 \%$ respectively had ADL treatment, followed by IFX with $36 \%$ of patients. Remaining patients were under ETA or GOL.

$46.3 \%$ of AS patients benefited from ADL treatment and $42 \%$ were on IFX. A percentage of 10.1 patients had ETA treatment and only one patient was on GOL.

Patient distribution in the two subgroups based on the type of biological agent is illustrated below.
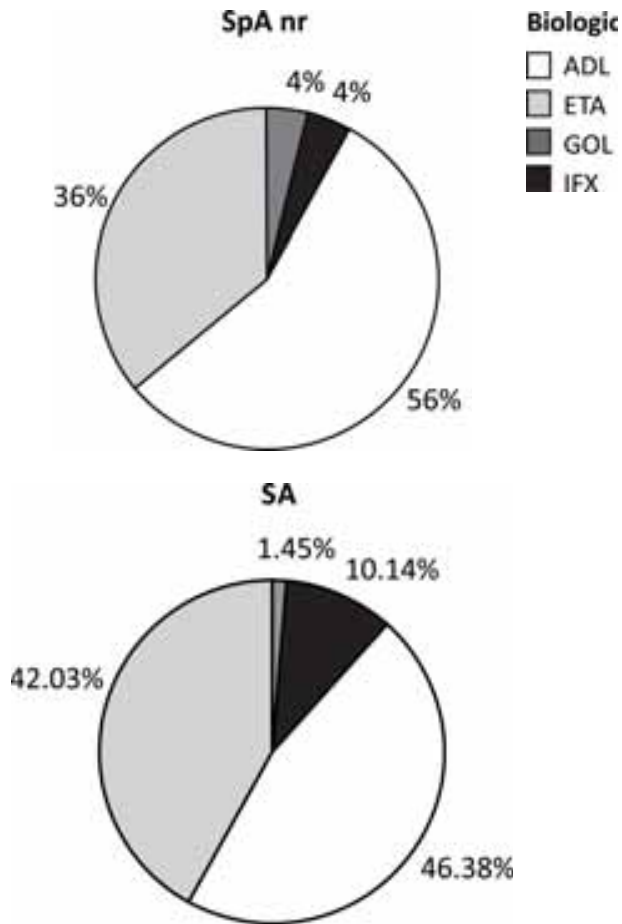

FIGURE 3. Anti-TNF agent distribution in the $n r-S p A$ and AS subgroups

$23.4 \%$ of patients had at least one therapeutical switch before actual therapy. The statistical data analysis did not detect significant correlations between the switch history and factors like age, gender or smoking.

The main cause of switch was in secondary nonresponder patients, while other identified causes were adverse events (eg. anafilaxis) or outdating the allowed interval of IFX administration if the treatment was previously paused.

According to the collected data, the time interval from symptom onset to establishing a diagnosis was of 39.9 \pm 55.6 months. The time length from the moment of diagnosis until initiation of biological therapy was $72.5 \pm 85.1$ months. This data is detailed in the image below. 


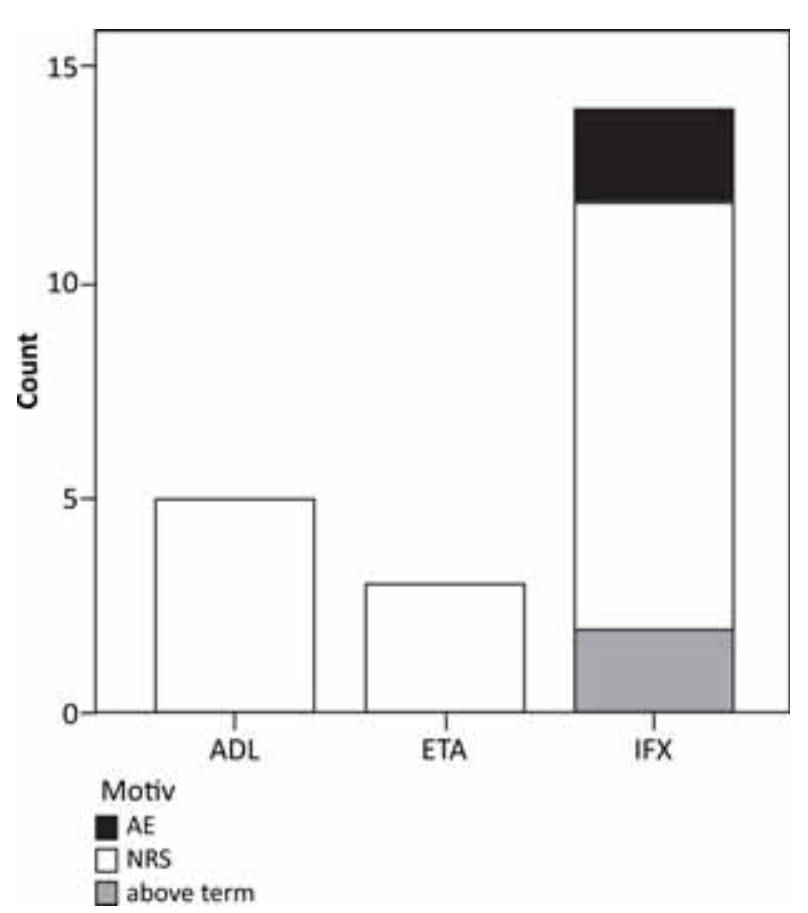

FIGURE 4. Causes of switch in the study group (AE = adverse events,

$N R S$ = secondary non-responders)

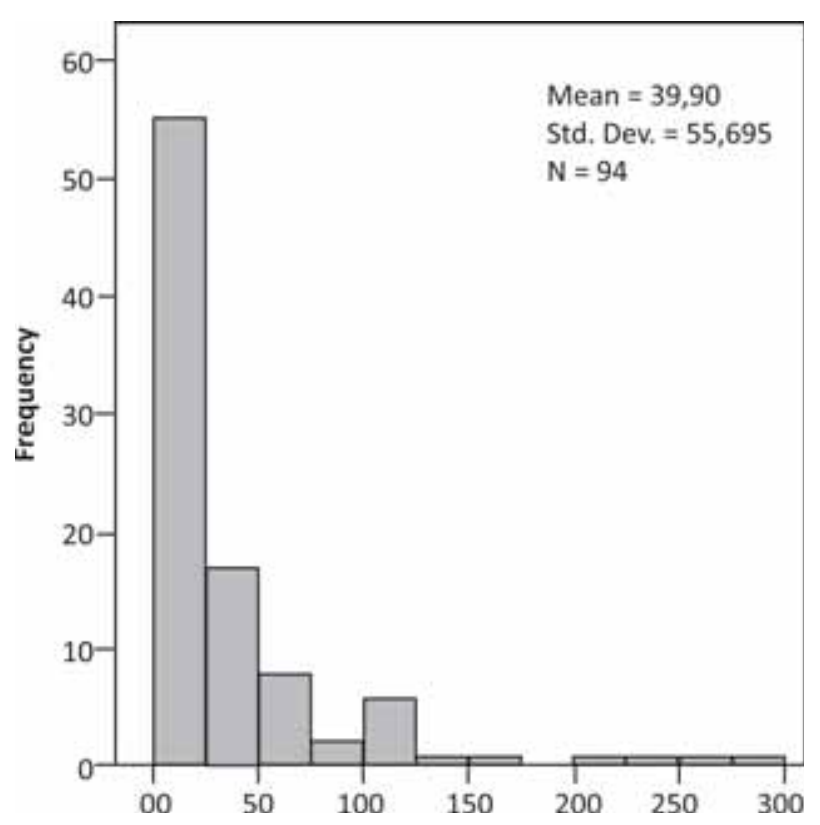

FIGURE 5. Interval from symptom onset to diagnosis

There is a delay between the first symptoms and the time of diagnosis, with a mean of 2.32 years for patients with nr-SpA and higher, of 3.5 for patients with AS $(\mathrm{P}=0.01)$.

Data records from regular follow-up visits allowed us to have a regular and accurate examination of patients' evolution, based on activity scores. Thus, we could assess patients according to ASDAS values

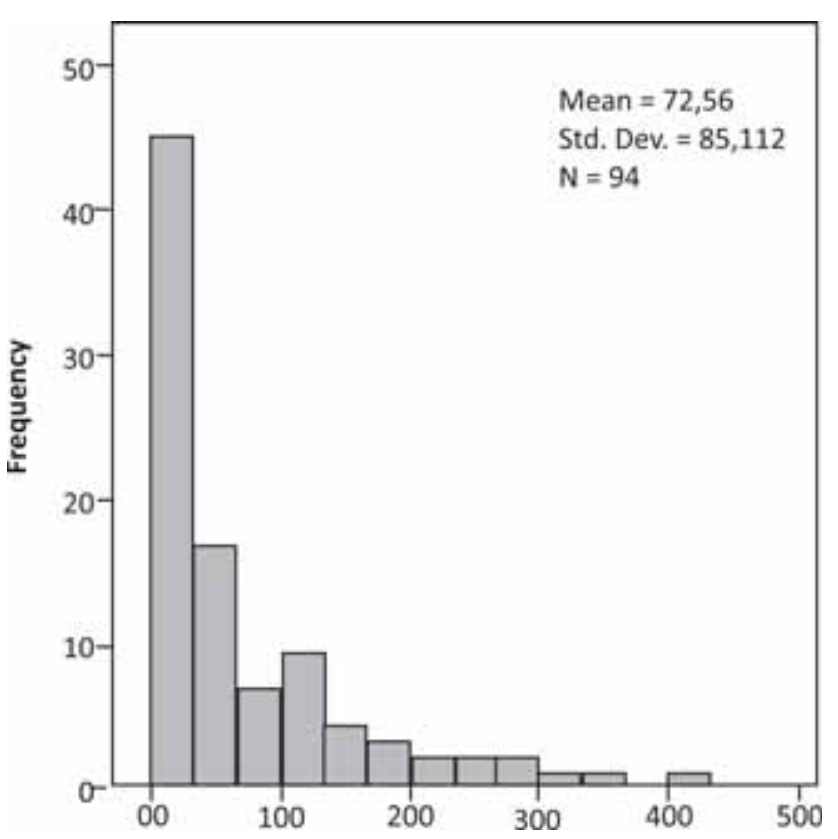

FIGURE 6. Interval from diagnosis to biologic therapy initiation

from the study inclusion point (present ASDAS) compared to previous activity scores which are mandatory in patient follow-up visits (previous ASDAS). The ASDAS score was calculated with the CRP value.

In the graphics below we illustrated the disease activity categories according to ASDAS in patients with nr-SpA in the two time points mentioned beforehand. So, we notice the percentage of patients that underwent an improvement of disease status, by passing from an active or intensely active disease category to an inferior one, namely those indicating a moderate or inactive disease and confirming the therapeutic benefits of the anti-TNF agent.

Similarly, the image below describes the AS patients' evolution based on ASDAS score values recorded in the study population in a six-month interval. In this subgroup, we observe a slower dynamic in changing disease activity categories, compared to nr-SpA patients.

Likewise, the possibility to calculate the delta ASDAS score ( $\triangle$ ASDAS) allowed us to objectify the level of improvement in patients under biological therapy between follow-up visits. This score represents the difference between the previous (anterior) ASDAS and the value of present ASDAS. If this difference is higher than 1.1, we consider the improvement to be significant and if it is more than 2, we evaluate the improvement as being a major one. A $\triangle$ ASDAS lower than 1.1 indicates lack of improvement. 

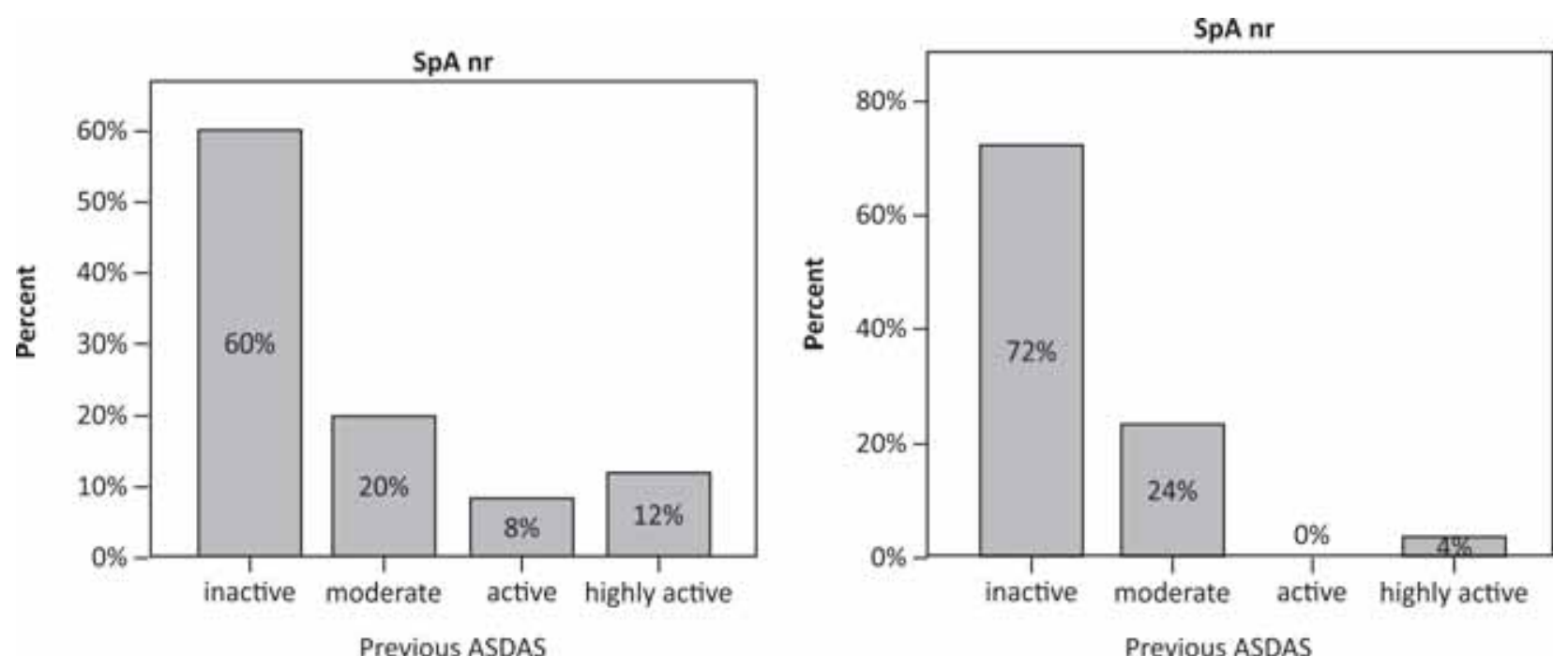

FIGURE 7. Nr-SpA patients' evolution according to ASDAS scores
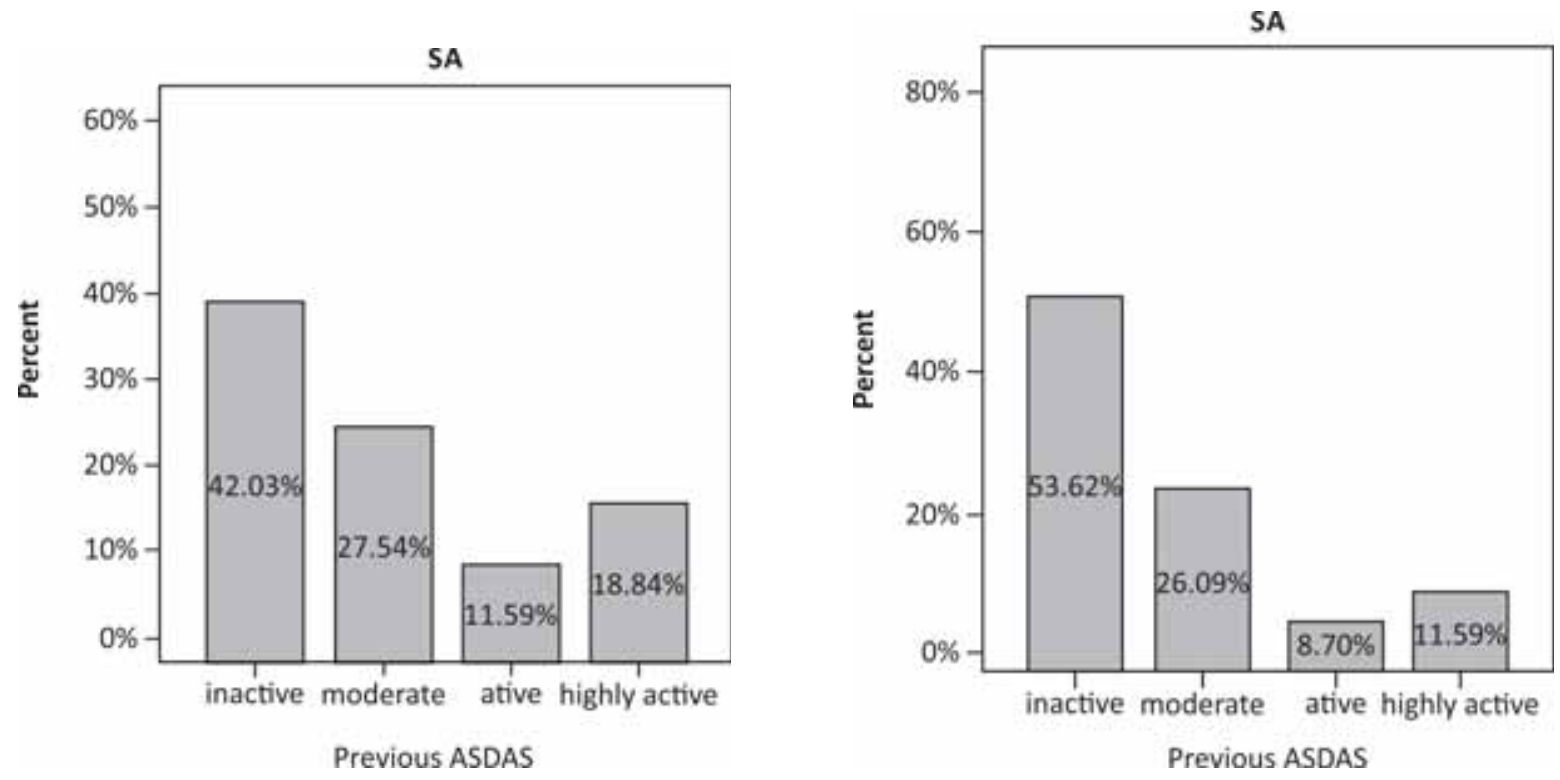

FIGURE 8. AS patients' evolution according to ASDAS scores
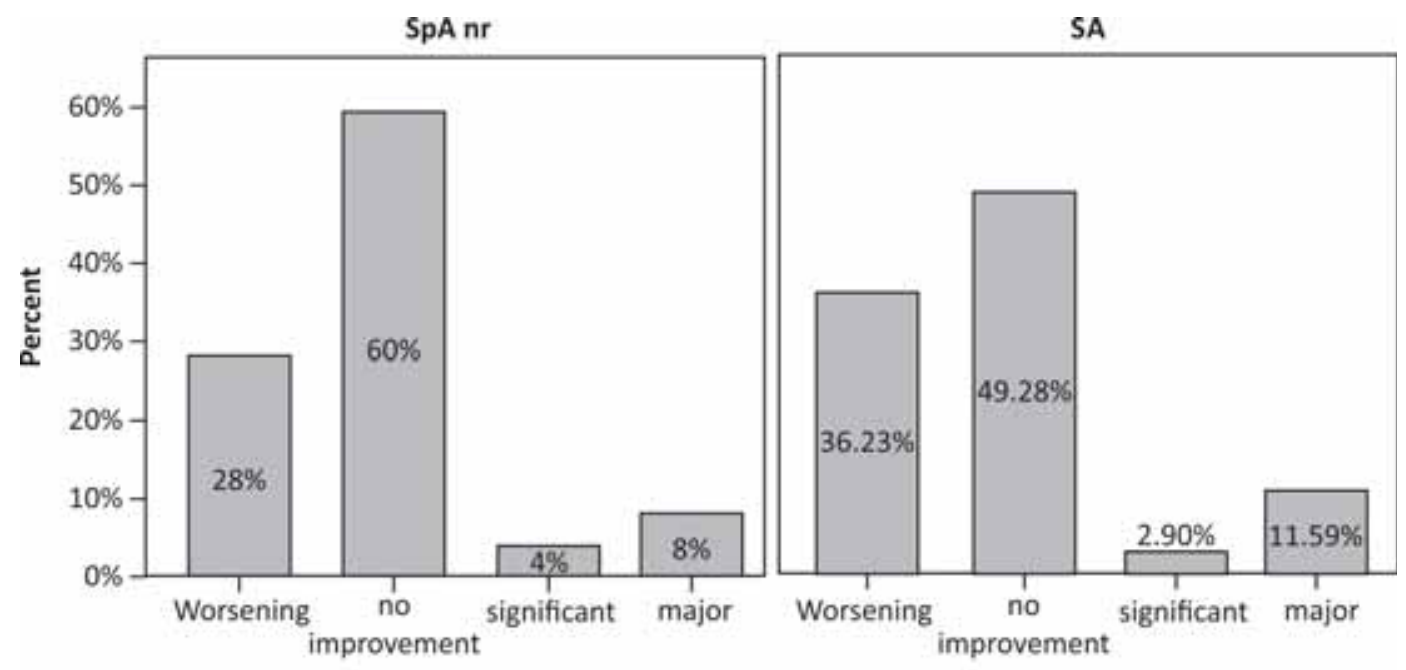

FIGURE 9. $\triangle A S D A S$ score in $n r-S p A$ and AS patients 
For patients with a negative $\triangle$ ASDAS at reevaluation (expressed in the figure below as "worsening"), the rheumatologist decided to do a therapeutical switch on a different anti-TNF agent.

Features of patients with an inactive disease at the study inclusion point, characterized by a BASDAI score lower than 4 and an ASDAS score under 1.3 are detailed below in Table 2.

TABLE 2. Characteristics of patients with inactive disease

\begin{tabular}{|l|c|c|c|c|c|}
\hline \multicolumn{7}{|c|}{ Group Statistics } \\
\hline & $\begin{array}{l}\text { Inactive } \\
\text { disease }\end{array}$ & $\mathrm{N}$ & Mean & $\begin{array}{c}\text { Std. } \\
\text { Deviation }\end{array}$ & $\begin{array}{c}\text { Std. Error } \\
\text { Mean }\end{array}$ \\
\hline \multirow{2}{*}{$\begin{array}{l}\text { Body mass } \\
\text { index }\end{array}$} & Yes & 55 & 25,25 & 4,118 &, 555 \\
\cline { 2 - 6 } & No & 39 & 28,12 & 4,357 &, 698 \\
\hline $\begin{array}{l}\text { Onset- } \\
\text { treatment } \\
\text { initiation } \\
\text { interval }\end{array}$ & Yes & 55 & 85,2182 & 78,27981 & 10,55525 \\
\cline { 2 - 7 } & No & 39 & 126,1538 & 101,71983 & 16,28821 \\
\hline $\begin{array}{l}\text { Disease } \\
\text { duration }\end{array}$ & Yes & 55 & 11,2364 & 6,96011 &, 93850 \\
\cline { 2 - 6 } $\begin{array}{l}\text { Age at } \\
\text { onset }\end{array}$ & Yes & 59 & 14,4872 & 8,99963 & 1,44109 \\
\cline { 2 - 6 } & No & 39 & 27,3846 & 10,92707 & 1,74973 \\
\hline
\end{tabular}

Data analysis indicates that patients with inactive disease had a significantly lower BMI compared to those with active disease (25.2 versus 28.1, $\mathrm{p}<0.05$ ).

Disease duration in patients who are currently in an inactive state of disease was more reduced than those with an active disease that is 11.2 compared to 14.4

Moreover, patients with signs of controlled disease initiated biological therapy with an anti-TNF agent earlier than other patients. The time length between the diagnosis was 85.2 months compared to 126.1 months for the second group.

Regarding the group in the present study, data showed that reaching an inactive state of disease was not influenced by variables as gender, smoking or HLA B27 presence.

\section{DISCUSSIONS}

Acknowledging the existence of the two patient categories, namely nr-SpA and AS, the existence of protective factors against pathological new bone formation should be investigated.

Study cohorts on nr-SpA include a higher rate of females compared to AS, therefore a role of the hormonal background in bone production is suggested
(12). In studies from Asia (13), the percentage of nrSpA female patients was almost twice higher than AS cohorts, while in studies from Europe and North America, women made up almost half of the nr-SpA study groups $(14,15)$. In the present study, the percentage of nr-SpA females was significantly higher compared to AS patients ( $40 \%$ versus $27.5 \%$ ).

The role of mechanical stress factors in male patients is still a matter of debate or whether these might aggravate the inflammatory processes, leading to a decline in mobility and functionality of the spine $(16,17)$.

Moreover, some studies suggest that patients with AS have higher levels of CRP and intense MRI inflammatory signals of the sacroiliac joints $(18,16)$.

Thus, a hypothesis was issued saying that both females and patients with low inflammation assessed through CRP or MRI actually progress slower to the radiographic stage of the disease, remaining in the $\mathrm{nr}$-SpA phase for a longer period of time (18).

The MRI technique is able to detect active inflammation and can detect patients in an early stage of the disease, when bone lesions are not yet irreversible. MRI lesions of sacroiliitis can be active or structural changes (19). The active ones include periarticular bone edema, synovitis and capsulitis and these ones are included in the ASAS criteria of nr-SpA (20). Structural lesions are bone erosions, subchondral sclerosis and fat metaplasia (21).

All nr-SpA patients included in our study group performed an MRI at the time of diagnosis that detected active sacroiliac lesions, while the x-ray ruled out the presence of sacroiliitis.

The GESPIC cohort from the German study initiated in 2000 compared 226 patients with nr-SpA under five years of evolution and 236 AS patients under 10 years (22). There were no notable differences between the two groups concerning the presence of HLA B27, arthritis, uveitis or disease activity measured with BASDAI, thus suggesting that nr-SpA and AS are in fact the same disease entitate (22).

In the present study that evaluates patients from a Romanian cohort, we did not record significant differences in HLA B27 gene, the frequency of uveitis or disease activity monitored through BASDAI and PtGA (Patient Global Assessment), this standing in agreement with the abovementioned published study.

However, there were differences regarding age and BMI as follows: patients with AS had a higher age at symptom onset and a higher BMI compared to 
nr-SpA patients. Moreover, patients with AS presented a higher CRP value than the nr-SpA, thus contributing to previous studies that state that objective inflammatory signs (CRP or MRI) are identified more frequently in patients with AS than in ones with $\mathrm{nr}-\mathrm{SpA}$ (16).

The study group included, however, a relatively small number of patients that hardened obtaining significant results.

$\mathrm{Nr}-\mathrm{SpA}$ also poses issues concerning therapeutic options in this stage of the disease, knowing that early initiation of treatment might prevent structural damage.

Anti-TNF alpha agents were tested in several randomized clinical trials in patients with $\mathrm{nr}-\mathrm{SpA}$, with favorable outcomes, especially on patients with recent onset disease, thus emphasizing the concept of ,window of opportunity” (23).

The target of biological therapy in patients from daily practice is obtaining remission, defined by ASAS partial remission criteria (pain $\leq 2$ on a $0-10$ scale, PtGA, BASFI, morning stiffness out of BASDAI score) or an ASDAS score of inactive disease, namely $\leq 1.3$.

The ASAS40 rate of response under biological therapy varied between 50 and $70 \%$ in several studies, compared to $12-17 \%$ for the placebo group, indicating the benefits of TNF inhibitors (12).

The ABILITY 1 study that evaluated the efficacy of ADL treatment in a nr-SpA patient cohort observed an ASAS40 response at 12 weeks for $36 \%$ of patients, compared to $12 \%$ in the placebo group, with a decrease in the MRI inflammatory signal $(24,25)$. A better response was observed in younger patients with a short disease duration and a high baseline CRP (25).

Same favorable results were obtained for ETA in the EMBARK study on a 48 week extended period and $60 \%$ of patients reached an inactive disease state, with an ASDAS score under 1.3 (26).

The study that assessed IFX plus naproxen response in patients with early axial SpA (INFAST, 2014 ) showed that $62 \%$ of them reached ASAS partial remission criteria at week 28 (27).

Another randomized, double-blind study followed the response to GOL in a $97 \mathrm{nr}-\mathrm{SpA}$ patient cohort and concluded that $56.7 \%$ of them obtained the ASAS40 response at 16 weeks compared to $23 \%$ in the placebo group (28).

The nr-SpA patients from the study group were under treatment with one of the four anti-TNFs and their evolution based on the ASDAS score was more favorable than in AS patients. The regular six month follow-up of nr-SpA patients shows the benefits of biological therapy on ASDAS disease categories, with a tendency to lower disease activity.

Among factors identified as being associated to an unsatisfactory outcome, published studies mention a short treatment duration (29) and a long disease evolution before treatment initiation (30).

In the present study we identified that in AS patients there is a significantly higher delay between disease onset and establishing the diagnosis (3.5 years versus 2.32 years in $\mathrm{nr}-\mathrm{SpA}$ patients). This delay shows a free disease evolution interval in patients with AS that can be responsible of irreversible structural changes that are visible on the x-rays at the time of diagnosis.

From the results of the present study, we also recommend prompt initiation of treatment, in a short interval after diagnosis. Patients with inactive disease in the study group began therapy in a mean 85.2 months from diagnosis. Moreover, shorter disease duration was confirmed in patients with inactive disease.

In order to maintain the disease in an inactive state, it is important to obtain weight control, knowing that these patients have a lower BMI compared to those with active disease.

According to our results, we suggest that patients require long term monitoring in order to assess the safety and efficacy of TNF inhibitors on Romanian patient populations. They also need to repeat MRI examination to score the level of sacroiliac inflammation.

\section{CONCLUSIONS}

- Nr-SpA patient group had a considerably higher percentage of females compared to the AS subgroup.

- Patients with AS presented higher values of CRP at follow-up visits as opposed to nr-SpA patients.

- There were no significant differences between nr-SpA and AS patients regarding the presence of HLA B27, BASDAI or PtGA scores, smoking status or frequency of uveitis.

- Features of patients with inactive disease consist in a lower BMI measure, shorter disease duration and early initiation of therapy with TNF inhibitor. 


\section{REFERENCES}

1. Akgul O., Ozgocmen S. Classification criteria for spondyloarthropathies. World J Orthop. 2011; 2(12):107-115. doi:10.5312/wjo.v2.i12.07.

2. Societatea Romana de Reumatologie. Ghiduri de Tratamente Biologice in Reumatologie.; 2015.http://view.publitas.com/amph/ ghiduri-de-tratamente-biologice-in-reumatologie/page/2-3.

3. Wendling D., Prati C., Claudepierre P., Guillot X., Breban M. Non-radiographic spondyloarthritis: A theoretical concept or a real entity? Jt Bone Spine. 2012; 79(6):531-533. doi:10.1016/j. jbspin.2012.06.009.

4. Rudwaleit M., van der Heijde D., Landewé R., et al. The development of Assessment of SpondyloArthritis international Society classification criteria for axial spondyloarthritis (part II): validation and final selection. Ann Rheum Dis. 2009; 68(6):777-783. doi:10.1136/ard.2009.108233.

5. Rudwaleit M., Khan MA., Sieper J. The challenge of diagnosis and classification in early ankylosing spondylitis: do we need new criteria? Arthritis Rheum. 2005; 52(4):1000-1008. doi:10.1002/art.20990.

6. Deodhar A., Strand V., Kay J., Braun J. The term "nonradiographic axial spondyloarthritis" is much more important to classify than to diagnose patients with axial spondyloarthritis. Ann Rheum Dis. 2016; 75(5):791-794. doi:10.1136/ annrheumdis-2015-208852.

7. Gleb Slobodin I.E. Non-Radiographic Axial Spondyloarthritis.

8. Bennett A.N., McGonagle D., O'Connor P., et al. Severity of baseline magnetic resonance imaging-evident sacroilitis and HLA-B27 status in early inflammatory back pain predict radiographically evident ankylosing spondylitis at eight years. Arthritis Rheum. 2008; 58(11):3413-3418. doi:10.1002/art.24024.

9. Poddubnyy D., Rudwaleit M., Haibel H., et al. Rates and predictors of radiographic sacroilitis progression over 2 years in patients with axial spondyloarthritis. Ann Rheum Dis. 2011; 70(8):1369-1374. doi:10.1136/ard.2010.145995.

10. Stolwijk C., Boonen A., van Tubergen A., Reveille J.D. Epidemiology of spondyloarthritis. Rheum Dis Clin North Am. 2012; 38(3):441-476. doi:10.1016/j.rdc.2012.09.003.

11. Strand V., Rao S.A., Shillington A.C., Cifaldi M.A., McGuire M., Ruderman E.M. Prevalence of axial spondyloarthritis in United States rheumatology practices: Assessment of SpondyloArthritis International Society criteria versus rheumatology expert clinical diagnosis. Arthritis Care Res (Hoboken). 2013; 65(8):1299-1306. doi:10.1002/acr.21994.

12. Slobodin Gleb E.I. Non-Radiographic Axial Spondyloarthritis. IMAJ. 2015; 17.

13. Jeong H., Yoon J.Y., Park E.J., et al. Clinical characteristics of nonradiographic axial spondyloarthritis in Korea: a comparison with ankylosing spondylitis. Int J Rheum Dis. 2015; 18(6):661-668. doi:10.1111/1756-185X.12458.

14. Ciurea A., Scherer A., Exer P., et al. Tumor Necrosis Factor a Inhibition in Radiographic and Nonradiographic Axial Spondyloarthritis: Results From a Large Observational Cohort. Arthritis Rheum. 2013; 65(12):3096-3106. doi:10.1002/art.38140.

15. Wallis D., Haroon N., Ayearst R., Carty A., Inman R.D. Ankylosing Spondylitis and Nonradiographic Axial Spondyloarthritis: Part of a Common Spectrum or Distinct Diseases? J Rheumatol. 2013; 40(12):2038-2041. doi:10.3899/jrheum.130588.

16. Baraliakos X., Braun J. Non-radiographic axial spondyloarthritis and ankylosing spondylitis: what are the similarities and differences?: Table 1. RMD Open. 2015; 1(Suppl 1):e000053. doi:10.1136/rmdopen-2015-000053.

17. Poddubnyy D., Brandt H., Vahldiek J., et al. The frequency of non-radiographic axial spondyloarthritis in relation to symptom duration in patients referred because of chronic back pain: results from the Berlin early spondyloarthritis clinic. Ann Rheum Dis. 2012; 71(12):1998-2001. doi:10.1136/annrheumdis-2012-201945.

18. Poddubnyy D., Sieper J. Similarities and differences between nonradiographic and radiographic axial spondyloarthritis. Curr Opin Rheumatol. 2014; 26(4):377-383. doi:10.1097/ BOR.0000000000000071.

19. Schueller-Weidekamm C., Mascarenhas V., Sudol-Szopinska I., et al. Imaging and Interpretation of Axial Spondylarthritis: The Radiologist's Perspective-Consensus of the Arthritis Subcommittee of the ESSR. Semin Musculoskelet Radiol. 2014; 18(03):265-279. doi:10.1055/s-0034-1375569.

20. Hermann K-G.A., Baraliakos X., van der Heijde D.M., et al. Descriptions of spinal MRI lesions and definition of a positive MRI of the spine in axial spondyloarthritis: a consensual approach by the ASAS/OMERACT MRI study group. Ann Rheum Dis. 2012; 71(8):1278-1288. doi:10.1136/ard.2011.150680.

21. Jans L., Coeman L., Van Praet L., et al. How sensitive and specific are MRI features of sacroiliitis for diagnosis of spondyloarthritis in patients with inflammatory back pain? JBR-BTR. 97(4):202-205. http://www.ncbi.nlm.nih.gov/ pubmed/25603626. Accessed November 4, 2016.

22. Rudwaleit M., Haibel H., Baraliakos X., et al. The early disease stage in axial spondylarthritis: Results from the german spondyloarthritis inception cohort. Arthritis Rheum. 2009; 60(3):717-727. doi:10.1002/art.24483.

23. Robinson P.C., Brown M.A., Baraliakos X., et al. The window of opportunity: a relevant concept for axial spondyloarthritis. Arthritis Res Ther. 2014; 16(3):109. doi:10.1186/ar4561.

24. Sieper J., van der Heijde D., Dougados M., et al. Efficacy and safety of adalimumab in patients with non-radiographic axial spondyloarthritis: results of a randomised placebo-controlled trial (ABILITY-1). Ann Rheum Dis. 2013; 72(6):815-822. doi:10.1136/ annrheumdis-2012-201766.

25. Van der Heijde D., Joshi A., Pangan A.L., et al. ASAS40 and ASDAS clinical responses in the ABILITY-1 clinical trial translate to meaningful improvements in physical function, health-related quality of life and work productivity in patients with non-radiographic axial spondyloarthritis. Rheumatology. 2016; 55(1):80-88. doi:10.1093/rheumatology/kev267.

26. Maksymowych W.P., Dougados M., van der Heijde D., et al. Clinical and MRI responses to etanercept in early non-radiographic axial spondyloarthritis: 48-week results from the EMBARK study. Ann Rheum Dis. 2016; 75(7):1328-1335. doi:10.1136/ annrheumdis-2015-207596.

27. Sieper J., Lenaerts J., Wollenhaupt J., et al. Efficacy and safety of infliximab plus naproxen versus naproxen alone in patients with early, active axial spondyloarthritis: results from the double-blind, placebo-controlled INFAST study, Part 1. Ann Rheum Dis. 2014; 73(1):101-107. doi:10.1136/annrheumdis-2012-203201.

28. Sieper J., van der Heijde D., Dougados M., et al. A Randomized, Double-Blind, Placebo-Controlled, Sixteen-Week Study of Subcutaneous Golimumab in Patients With Active Nonradiographic Axial Spondyloarthritis. Arthritis Rheumatol. 2015; 67(10):27022712. doi:10.1002/art.39257.

29. Lubrano E., Perrotta F.M., Marchesoni A., et al. Remission in nonradiographic axial spondyloarthritis treated with anti-tumor necrosis factor- $\alpha$ drugs: an Italian multicenter study. J Rheumatol. 2015; 42(2):258-263. doi:10.3899/jrheum.140811.

30. Sieper J., van der Heijde D., Dougados M., et al. Efficacy and safety of adalimumab in patients with non-radiographic axial spondyloarthritis: results of a randomised placebo-controlled trial (ABILITY-1). Ann Rheum Dis. 2013; 72(6):815-822. doi:10.1136/annrheumdis-2012-201766. 